\title{
Effect of the surfactant benzalkonium chloride in the sorption of paraquat and cadmium on montmorillonite
}

\section{Romina llari, Mariana Etcheverry, Cristina Zenobi and Graciela Zanini*}

\author{
INQUISUR, Departamento de Química, \\ Universidad Nacional del Sur. Av. Alem 1253, \\ Bahía Blanca 8000, Argentina \\ E-mail: romina.ilari@uns.edu.ar \\ E-mail: mariana.etcheverry@uns.edu.ar \\ E-mail:mzenobi@criba.edu.ar \\ E-mail: gzanini@uns.edu.ar \\ ${ }^{*}$ Corresponding author
}

\begin{abstract}
Pesticides, heavy metals and surfactants can share the same region or site in the environment and thus they may compete for the surface of minerals. A competitive study of the adsorption between the cationic surfactant benzalkonium chloride (BAC) with the heavy metal cadmium $(\mathrm{Cd}(\mathrm{II}))$ and the cationic herbicide paraquat (PQ) on montmorillonite is presented. Adsorption isotherms for $\mathrm{BAC}, \mathrm{PQ}$ and $\mathrm{Cd}(\mathrm{II})$ were performed in single solute systems and also in binary solute systems, $\mathrm{PQ}+\mathrm{BAC}$ and $\mathrm{Cd}(\mathrm{II})+\mathrm{BAC}$ to evaluate the effects of BAC on the adsorption of the other two substances. The affinities of BAC and $\mathrm{PQ}$ were strong and similar, thus BAC affected significantly the adsorption of PQ and vice versa. The affinity of Cd(II) for the montmorillonite surface was low, thus BAC affected appreciably $\mathrm{Cd}$ (II) adsorption, but the heavy metal did not modify BAC adsorption. XRD data show that BAC molecules control the magnitude of the basal spacing.
\end{abstract}

Keywords: BAC; benzalkonium chloride; paraquat; cadmium; heavy metal; montmorillonite; competitive adsorption; isotherms; surfactant; pesticide.

Reference to this paper should be made as follows: Ilari, R., Etcheverry, M., Zenobi, C. and Zanini, G. (2014) 'Effect of the surfactant benzalkonium chloride in the sorption of paraquat and cadmium on montmorillonite', Int. J. Environment and Health, Vol. 7, No. 1, pp.70-82.

Biographical notes: Romina Ilari is a PhD student in Chemistry. Her current position is Teaching Assistant at Universidad Nacional del Sur, Bahía Blanca, Argentina, and she is a fellow of the Scientific Research Council of Argentina (CONICET). Her research interest focuses on surface reactivity of minerals, adsorption-desorption of pesticides and surfactants.

Mariana Etcheverry has a $\mathrm{PhD}$ in Chemistry. She is a full-time Teaching Assistant at Universidad Nacional del Sur, Bahía Blanca, Argentina. Her current research interest focuses on adsorption-desorption of heavy metals and surfactants, and new adsorbent materials to retain organic and inorganic contaminants. 
Cristina Zenobi has a $\mathrm{PhD}$ in chemistry. She is a full-time Teaching Assistant at Universidad Nacional del Sur, Bahía Blanca, Argentina. Her current research interest focuses on adsorption-desorption of heavy metals and surfactants, and new adsorbent materials to degrade contaminants.

Graciela Zanini has a PhD in Chemistry. She is a Researcher for the Scientific Research Council of Argentina (CONICET) and a Professor at Universidad Nacional del Sur, Bahía Blanca, Argentina, teaching in inorganic and general chemistry courses. Her research interest focuses on geochemistry, reactivity of mineral surface, adsorption-desorption of pollutants as pesticides, heavy metals and surfactants, new adsorbent materials to retain contaminants.

\section{Introduction}

Pollutants are spread around the world and most of them proceed from human activities: intensive farming (Bottoni et al., 2013), waste water (McArthur et al., 2012), oil pollution (Larsen et al., 2007), industrial waste (Carrer and Leardi, 2006) and household waste (Slack et al., 2005) are several examples of activities responsible for pollution. These activities introduce into the environment different kinds of substances, such as pesticides, heavy metals and surfactants. Pesticides are mostly introduced by agriculture practices (Bedmar et al., 2011; Hillocks, 2012). Heavy metals, in their anthropogenic origin, are directly or indirectly discharged into the environment as a consequence of the development of industries, as metal plating facilities, mining operations, fertiliser industries, batteries, etc. (Fu and Wang, 2011). Surfactants are added to the environment as a result of their wide use as cleaning agents and disinfectants (Van de Voorde et al., 2012), as adjuvants in commercial formulations of pesticides, and even as dissipaters in oil spills (Krogh et al., 2003; Salehian et al., 2012).

Pesticides and heavy metals are widely recognised as dangerous substances and their polluting properties are well known. Surfactants, on the other hand, are usually considered as non-toxic and non-polluting substances, and therefore they are spread into the environment without any control or concern. People are more worried about the toxicity of pesticides and heavy metals than about surfactants, but it is important to note that surfactants in the environment can influence the adsorption of other pollutants and they can be responsible for modifying the mobility, bioavailability and consequent toxicity of pesticides and heavy metals (Krogh et al., 2003; Hayes et al., 1995; Iglesias Gimenez et al., 1996).

Surfactants are molecules that have a polar head and a long tail of carbon atoms; there are cationic, anionic, non-ionic and zwitterionic surfactants (Holmberg et al., 2006). They have different uses and their global production currently stands at around 12 million tons per year and higher growth is expected (Edser, 2008). Cationic surfactants such as quaternary ammonium compounds (QACs) are high production volume chemicals that constitute a large fraction of the cationic surfactant market ( $\mathrm{Li}$ and Brownawell, 2010). QAC are used intensively in different activities, i.e., disinfectant in agriculture, food handling, commercial, institutional, industrial, residential and medical settings (EPA, 2006). Therefore, QAC are easily dispersed in the environment (Kümmerer et al., 1997; Ferrer and Furlong, 2001, 2002) and it is highly probable that they can share the same site with pesticides and heavy metals in the environment. As an example, Li and Brownawell 
(2010) inform the presence of different QAC in sediments nearby the Hudson River, whereas Feng et al. (1998) inform the presence of heavy metals in the sediments of the same zone. Therefore, it is very important to study the effects of surfactants on the adsorption properties of pesticides and heavy metals, to understand the fate of these pollutants in the environment.

There are some papers reporting the effects of surfactants on the adsorption of heavy metals or pesticides. Hayes et al. (1995), for example, presented a study of the influence of three alkyl trimethylammonium chloride surfactants (with 8, 12 and 16 carbon atoms in their tails) on the adsorption of $\mathrm{Co}$ (II) and $\mathrm{Sr}$ (II) onto several soil minerals (quartz, montmorillonite, kaolinite). They found that the presence of these surfactants did not affect desorption of heavy metals from quartz significantly, but affected desorption from montmorillonite and kaolinite. Similarly, Li et al. (2002) posted that QAC decreased the adsorption of $\mathrm{Cs}(\mathrm{I}), \mathrm{Sr}(\mathrm{II}), \mathrm{La}(\mathrm{III}), \mathrm{Pb}(\mathrm{II})$ and $\mathrm{Zn}(\mathrm{II})$ on zeolite. Esumi et al. (1998) reported the effects of three different QAC compounds on the adsorption of PQ on laponite, and observed that the three compounds competed with PQ for the clay mineral surface. Although there are more papers on these topics in the literature, most publications deal with adsorption on different solids of pesticides (Gevao et al., 2000) or heavy metals (Bhattacharyya and Gupta, 2008). However, the information published about competitive adsorption between pesticides/surfactants and heavy metal/surfactants in binary systems are very limited.

The aim of this paper is to show in two examples the effects of the cationic surfactant benzalkonium chloride (BAC), a well known QAC, on the adsorption behaviour of Cd(II) and paraquat $(\mathrm{PQ})$ on montmorillonite.

\section{Materials and methods}

PQ, 1'-dimethyl-4,4'-bipyridinium dichloride (99.0\%), was supplied from Supelco and BAC, dodecyl benzyldimethylammonium chloride, (99.0\%) was from Aldrich. Their molecular structures are shown in Figure 1. The critical micelle concentration (CMC) of BAC was $3.69 \mathrm{mM}$ in $0.02 \mathrm{M} \mathrm{NaCl}$ solution and $1.25 \mathrm{M}$ in $0.02 \mathrm{M} \mathrm{NaNO}_{3}$ solution. These values were determined by preparing several BAC solutions in the corresponding electrolyte and by measuring the size of the molecular aggregates using a Zetasizer ZS90 instrument (Malvern, UK). The concentration at which the size started to increase abruptly was taken as the CMC. The cadmium salt was $\mathrm{Cd}\left(\mathrm{NO}_{3}\right)_{2} \cdot 4 \mathrm{H}_{2} \mathrm{O}(99 \%)$ from Riedel-de Haën.

The clay used in this study, Na-montmorillonite ( $99.4 \%$ purity), was obtained from Lago Pellegrini (Río Negro, Argentina). It has a cation exchange capacity (CEC) of $0.91 \mathrm{mEq} \mathrm{g}^{-1}$, as measured by adsorption of tetraethylenepentamine copper(II), $[\mathrm{Cu} \text { (tetren) }]^{2+}$, following the method of Meier and Kahr (1999).

Other chemicals $\left(\mathrm{NaCl}, \mathrm{HCl}, \mathrm{NaNO}_{3}, \mathrm{HNO}_{3}, \mathrm{NaOH}, \mathrm{CHCl}_{3}\right.$, Orange II) were analytical grade chemicals and all materials were used without further treatment or purification. 
Figure 1 Molecular structure of (a) PQ and (b) BAC
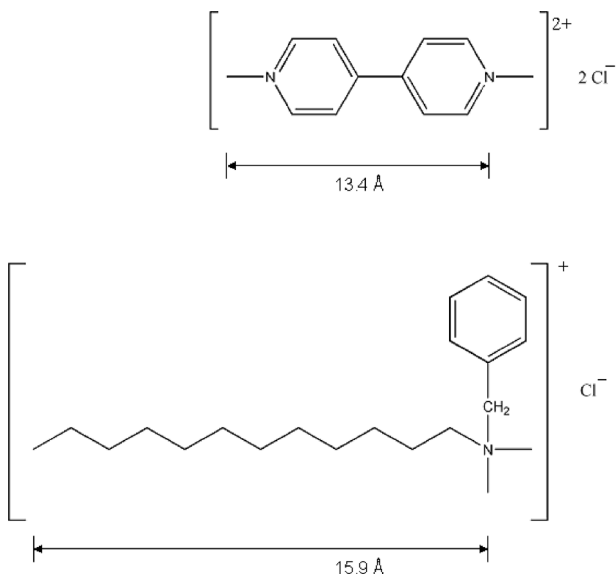

(b)

\section{$2.1 \quad B A C-P Q$}

Adsorption isotherms were performed in single solute systems and in binary solute systems. For all experiments, stock montmorillonite dispersion was prepared by dispersing $5 \mathrm{~g}$ in 11 of $0.02 \mathrm{M} \mathrm{NaCl}$. The dispersion was equilibrated for $4 \mathrm{~h}$ and adjusted to $\mathrm{pH} 6$ by addition of $0.1 \mathrm{M} \mathrm{HCl}$.

pH 6 was chosen for the experiments because this is a very common soil $\mathrm{pH}$ value (Zanini et al., 2009; Séquaris et al., 2013). In addition, although investigating the effects of $\mathrm{pH}$ on BAC and PQ adsorption is out of the scope of this paper, only small changes in adsorption are expected by changing $\mathrm{pH}$. This is because the positive charge of BAC molecules is independent of $\mathrm{pH}$, and because structural ( $\mathrm{pH}$ independent) charges in montmorillonite are dominant over variable ( $\mathrm{pH}$ dependent) charges (Bradbury and Baeyens, 1997; Avena and De Pauli, 1998; Bourg et al., 2007).

\subsubsection{PQ and BAC isotherms in single solute system}

Adsorption isotherms were obtained by performing batch adsorption experiments. $1.25 \mathrm{ml}$ of the stock dispersion were placed in $50 \mathrm{ml}$ polycarbonate centrifuge tubes, proper volumes of $\mathrm{NaCl}$ solution and appropriate aliquots of surfactant or herbicide solutions were added to cover initial concentration ranges from 0.025 to $0.625 \mathrm{mEq}^{-1}$ for BAC and from $0.050 \mathrm{mEq}^{-1}$ to $0.600 \mathrm{mEq}^{-1}$ for PQ. The final volume in each tube was $20 \mathrm{ml}$. Small amounts of either $\mathrm{NaOH}$ or $\mathrm{HCl}$ solutions were added to achieve a constant $\mathrm{pH}(6.0 \pm 0.1)$ in all experiments. The tubes were shaken end-to-end during $24 \mathrm{~h}$ to ensure equilibration, even though preliminary kinetic experiments showed that equilibration with BAC was reached already after $25 \mathrm{~min}$ and with PQ after $10 \mathrm{~min}$ of reaction. The tubes were then centrifuged at $1558 \mathrm{~g}$ for $15 \mathrm{~min}$ and the supernatants were withdrawn and PQ and BAC quantified. The amount of surfactant and herbicide retained by the solid $\left(\mathrm{Q} ; \mathrm{mEq} \mathrm{g}^{-1}\right)$ was calculated with the equation $Q=V\left(C_{0}-C_{\mathrm{eq}}\right) / m$, where $V(\mathrm{l})$ is the final volume in each tube, $C_{0}$ and $C_{\mathrm{eq}}\left(\mathrm{mEq} \mathrm{l}^{-1}\right)$ are the initial and equilibrium surfactant concentrations, respectively, and $m(\mathrm{~g})$ is the mass of adsorbent.

The concentrations of PQ and BAC in the supernatant were quantified by UV-Vis spectroscopy using an Agilent $8453 \mathrm{UV}-\mathrm{V}$ is diode array spectrophotometer. PQ was 
quantified at $258 \mathrm{~nm}\left(\varepsilon=21906 \mathrm{M}^{-1} \mathrm{~cm}^{-1}\right)$ and $\mathrm{BAC}$ was quantified using the dye method (Few and Ottewill, 1956).

\subsection{2 $P Q$ and $B A C$ isotherms in binary solute system $P Q+B A C$}

Adsorption experiments in $\mathrm{PQ}+\mathrm{BAC}$ systems were performed in $0.02 \mathrm{M} \mathrm{NaCl}$ solutions at different initial concentrations $\left(\mathrm{mEq} \mathrm{1}{ }^{-1}\right)$ ratios $(\mathrm{BAC} / \mathrm{PQ}=0.1 ; 0.5 ; 1$; and 3$)$. For these experiments, solutions of surfactant and herbicide were added simultaneously to the stock montmorillonite dispersion to cover total concentration $\mathrm{PQ}+\mathrm{BAC}$ ranges from $0.075 \mathrm{mEq}^{-1}$ to $0.675 \mathrm{mEq} \mathrm{l}^{-1}$. The procedure to perform the isotherms was equal to the employed with single solute systems (2.1.1). Equilibration also took place in around $25 \mathrm{~min}$, although shaking was performed during $24 \mathrm{~h}$ as for single solute systems.

\section{$2.2 \quad B A C-C d(I I)$}

Adsorption isotherms were also performed in single and in binary solute systems. A stock dispersion of montmorillonite was prepared by dispersing $5 \mathrm{~g}$ of clay in 11 of $0.02 \mathrm{M}$ $\mathrm{NaNO}_{3}$. The dispersion was equilibrated for $4 \mathrm{~h}$ and adjusted to $\mathrm{pH} 5$ by addition of $0.1 \mathrm{M} \mathrm{HNO}_{3}$.

\subsubsection{BAC and Cd(II) isotherms in single solute system}

Adsorption experiments were conducted as for BAC and PQ isotherms (2.1.1). The same procedure was used in the experiments, except that the supporting electrolyte was $0.02 \mathrm{M}$ $\mathrm{NaNO}_{3}$, the $\mathrm{pH}$ was $5.0 \pm 0.1$, and the initial concentration ranges were from $0.025 \mathrm{mEq}^{-1}$ to $0.725 \mathrm{mEq}^{-1}$ for BAC and $0.050 \mathrm{mEq}^{-1}$ to $1.0 \mathrm{mEq}^{-1}$ for $\mathrm{Cd}(\mathrm{II})$. $\mathrm{pH} 5$ was selected to ensure that the dominating Cd species is $\mathrm{Cd}^{2+}$ (Baes and Mesmer, 1976). BAC concentration was measured as mentioned above and $\mathrm{Cd}(\mathrm{II})$ concentration was quantified using an atomic absorption spectrometer (Perkin Elmer AAnalyst 200).

\subsubsection{BAC and $C d(I I)$ isotherms in binary solute system $C d(I I)+B A C$}

Adsorption isotherms in $\mathrm{Cd}(\mathrm{II})+\mathrm{BAC}$ systems were performed in $0.02 \mathrm{M} \mathrm{NaNO}_{3}$. Preliminary experiments with ratios $\mathrm{BAC} / \mathrm{Cd}(\mathrm{II})=1,2$ and 3 in the concentration range from $0.025 \mathrm{mEq} \mathrm{l}^{-1}$ to $0.725 \mathrm{mEq}^{-1}$ showed that Cd(II) adsorption on montmorillonite was almost insignificant. Therefore, conditions in these systems were changed with respect to $\mathrm{PQ}+\mathrm{BAC}$ systems to produce gradual changes in $\mathrm{Cd}(\mathrm{II})$ adsorption by changing $\mathrm{BAC}$ concentration. Each cadmium isotherm covers the concentration range from $0.025 \mathrm{mEq}^{-1}$ to $0.725 \mathrm{mEq}^{-1}$ in presence of different initial BAC concentrations: $0.025,0.075,0.125,0.175,0.225,0.275,0.325,0.525$ and $0.750 \mathrm{mEq}^{-1}$. For the experiments aliquots of the stock solutions of surfactant and cadmium were added simultaneously to the montmorillonite dispersion.

\subsection{Powder X-ray diffraction (XRD)}

Clay samples with adsorbed BAC, PQ, Cd(II) and mixtures PQ+BAC and $\mathrm{Cd}(\mathrm{II})+\mathrm{BAC}$ were examined by XRD to determine changes in the basal spacing. The clay pellet in the centrifuge tubes remaining after an adsorption isotherm experiment was dispersed in $1 \mathrm{ml}$ 
of supernatant, sonicated for $1 \mathrm{~min}$, and the dispersion spread onto a glass support and allowed to dry at room temperature for two days before the XRD measurement. Diffraction patterns were recorded with a Rigaku D-Max III-C diffractometer applying monochromated $\mathrm{Co}-\mathrm{K} \alpha$ radiation at $35 \mathrm{kV}$ and $15 \mathrm{~mA}$, covering diffraction angles from 3 to $30^{\circ} 2 \theta$, and with a scanning rate of $1.5^{\circ} 2 \theta \mathrm{min}^{-1}$. In the case of BAC and PQ, five samples from each isotherm at initial concentrations from $0.05 \mathrm{mEq}^{-1}$ to $0.35 \mathrm{mEq} \mathrm{l}^{-1}$ for $\mathrm{PQ}, 0.075 \mathrm{mEq} \mathrm{l}^{-1}$ to $0.375 \mathrm{mEq} \mathrm{l}^{-1}$ for $\mathrm{BAC}$ and $0.075 \mathrm{mEq}^{-1}$ to $0.375 \mathrm{mEq}^{-1}$ for (BAC+PQ) were chosen to cover a wide range of concentration and surface coverage. In the case of BAC and $\mathrm{Cd}(\mathrm{II})$, six samples from each isotherm at initial concentrations from $0.025 \mathrm{mEq}^{-1}$ to $0.325 \mathrm{mEq}^{-1}$ for $\mathrm{Cd}(\mathrm{II})$ and $\mathrm{BAC}$, and from $0.025 \mathrm{mEq}^{-1}$ to $0.325 \mathrm{mEq}^{-1}$ for $\mathrm{Cd}(\mathrm{II})+\mathrm{BAC}$ were chosen.

\section{Results and discussion}

Montmorillonite is a expandable clay, and can retain cationic chemicals into the interlayer by exchanging them with the raw inorganic cations present. This cationic exchange leads to changes in the basal spacing $\left(\mathrm{d}_{001}\right)$ depending on the amount and size of the molecules retained (Spark, 2003). Figure 2(a)-(c) show as an example the diffraction patterns of montmorillonite with different amounts of BAC and PQ adsorbed in single and binary solute systems. The diffraction patterns are typical for these kind of molecules adsorbed on montmorillonite (Zanini et al., 2013; Han et al., 2010). In absence of adsorbed $\mathrm{BAC}$ and $\mathrm{PQ}$, there is a diffraction peak that corresponds to an average basal spacing of $12.3 \AA$, a normal value for Na-exchanged montmorillonites (Kwolek et al., 2003; Tahani et al., 1999). For montmorillonite with adsorbed BAC in single solute systems (Figure 2(a)) the peak shifts to lower diffraction angles, showing that BAC adsorption increases the $\mathrm{d}_{001}$ spacing as a result of its incorporation in the interlayer. With adsorbed PQ in single solute systems (Figure 2(b)), the peak shifts only slightly to lower diffraction angles as a consequence of PQ adsorption. In the case of the binary solute system where both BAC and PQ are adsorbed (Figure 2(c)), the diffraction peak appears at the position of the BAC peak (single solute) but no at the position of the PQ peak (single solute). This seems to indicate that when both BAC and PQ are adsorbed, adsorbed BAC controls the basal spacing, even though PQ would be also located in the interlayer. In all cases, diffractions peaks were rather symmetric and no evidence of heterogeneity was observed. The changes in the basal spacing for montmorillonite with adsorbed BAC and PQ in single and binary solute systems are summarised in Figure 2(d). For BAC in single solute system the basal spacing changed linearly from $12.3 \AA$ to 16.7 ̊̊, whereas for PQ it changed only slightly from $12.3 \AA$ to $12.5 \AA$. For binary solute systems 25 points are shown (five points per each one of the five BAC/PQ ratios investigated). The basal spacing changed linearly from $12.3 \AA$ to $16.2 \AA$, similarly to what occurs with pure BAC, suggesting again that in binary solute systems the basal spacing is mainly controlled by the presence of the surfactant.

Although not shown, similar XRD results were obtained in montmorillonite samples with adsorbed $\mathrm{BAC}$ and $\mathrm{Cd}(\mathrm{II})$. The basal spacing changed from $12.3 \AA$ to $16.1 \AA$ for BAC and decreased slightly from $12.3 \AA$ to $12.1 \AA$ for $\mathrm{Cd}(\mathrm{II})$. In binary systems $\mathrm{Cd}(\mathrm{II})+\mathrm{BAC}$, the basal spacing changed from $12.3 \AA$ to $16.8 \AA$, depending mainly on the amount of BAC adsorbed and not on the amount of $\mathrm{Cd}(\mathrm{II})$ adsorbed. 
Figure 2 XRD patterns of montmorillonite with different amounts of (a) BAC adsorbed in single solute system and (b) PQ adsorbed in single solute system. The numbers listed to the right represent the amount of $\mathrm{BAC}$ or PQ adsorbed in $\mathrm{mEq} \mathrm{g}^{-1}$. (c) XRD patterns of montmorillonite with $\mathrm{BAC}$ and $\mathrm{PQ}$ adsorbed in binary solute system at $\mathrm{BAC} / \mathrm{PQ}=1$ compared to the corresponding patterns with $\mathrm{BAC}$ and $\mathrm{PQ}$ in single solute system. (d) Evolution of the $\mathrm{d}_{001}$ basal spacing at different amount of: $(O)$ BAC adsorbed in single solute system, (ם) PQ adsorbed in single solute system; and BAC adsorbed in binary solute system at different BAC/PQ ratios: $(\triangleright) 0.1 ;(\bigcirc) 0.5 ;(\boldsymbol{\Delta}) 1 ;(\square) 2 ;(\triangle) 3$
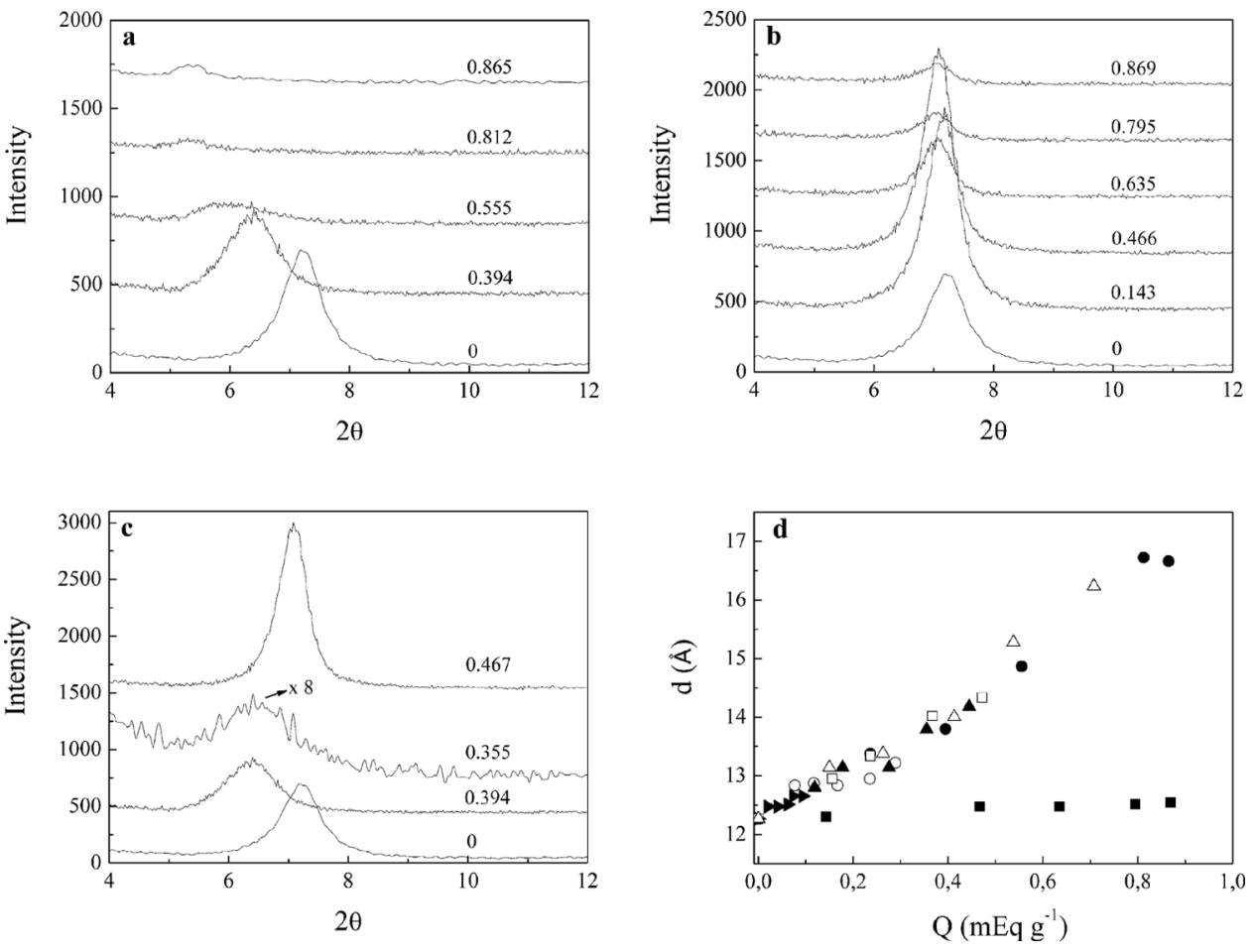

\subsection{Effect of $B A C$ in $P Q$ sorption}

Figure 3 shows the adsorption isotherms of BAC and PQ onto Na-montmorillonite for single solute systems. In both cases the adsorption increases abruptly at low concentrations and reached a plateau with a maximum adsorption at around $0.91 \mathrm{mEq} \mathrm{g}^{-1}$, a value that is equal to the CEC of the Na-montmorillonite. The data show that under the studied conditions BAC and PQ were mainly adsorbed by a cation exchange process, where sodium ions were replaced by either the positively charged surfactant or the positively charged herbicide. The results for PQ are similar to those reported by Rytwo et al. (1996) for cation exchange process of this herbicide in similar conditions with others divalent organic cations (diquat, crystal violet and acriflavine) on montmorillonite. The results for BAC are very similar to those reported by Zanini et al. (2013). These authors, in addition, showed that working at higher concentrations there was an extra and important adsorption due to surface micellisation as a consequence of tail-to-tail interactions. The surface micellisation started to be important at concentrations around $0.4 \mathrm{mM}$, which is an order of magnitude lower than the CMC of BAC in solution. A similar process was reported by Kwolek et al. (2003). This kind of surface 
micellisation is negligible under the conditions of Figure 3 because the concentrations investigated were lower than $0.4 \mathrm{mM}$, and thus only electrostatic interactions would be important.

Figure 4 shows the PQ and BAC adsorption isotherms in binary solute systems, at different $\mathrm{BAC} / \mathrm{PQ}$ ratios. In the case of PQ (Figure 4(a)), its adsorption decreases as the $\mathrm{BAC} / \mathrm{PQ}$ ratio increases. In the case of BAC (Figure 4(b)), its adsorption increases as the BAC/PQ ratio increases. On the other hand, it is possible to note in Figure 4(a) that at ratios higher than $0.5 \mathrm{PQ}$ adsorption curves show a decrease in adsorption as the equilibrium concentration increases for concentrations higher than $0.025 \mathrm{mEq}^{-1}$. All these data are consistent with a competitive adsorption between BAC and PQ on the permanently charged sites of montmorillonite. A similar competition was shown by Rytwo et al. (1996) for PQ, diquat and other divalent herbicides. Atun et al. (2010), on the other hand, reported this kind of competitive mechanism between the cationic dye toluidine blue and the cationic surfactant cetyltrimethylammonium bromide adsorbed onto geological materials as clay (containing quartz, mica, calcite, kaolinite, feldspar and montmorillonite) and sandstone (containing quartz, calcite and feldspar) collected from Turkey.

Figure 3 Adsorption isotherms of PQ ( $\mathbf{\square})$ and $\operatorname{BAC}(\bullet)$ on montmorillonite

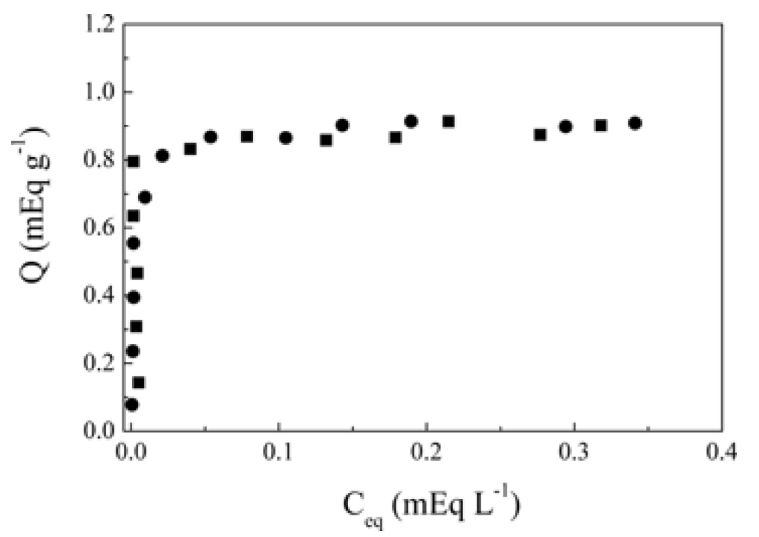

\subsection{Effect of BAC in Cd(II) sorption}

Figure 5 shows the adsorption isotherms of $\mathrm{Cd}(\mathrm{II})$ and $\mathrm{BAC}$ on Na-montmorillonite in single solute systems. Cd(II) adsorption is low when compared with BAC adsorption. $\mathrm{Cd}$ (II) adsorption did not reached the CEC of the Na-montmorillonite, even though $\mathrm{C}_{\mathrm{eq}}$ is rather high. This behaviour for $\mathrm{Cd}(\mathrm{II})$ adsorption at $\mathrm{pH}$ around 5 is similar to that found by Gupta and Bhattacharyya (2008). BAC adsorption, on the other hand, reaches the CEC of montmorillonite already at $\mathrm{C}_{\mathrm{eq}}=0.05 \mathrm{mEq}^{-1}$, indicating that $\mathrm{BAC}$ has a stronger affinity for the clay surface than $\mathrm{Cd}(\mathrm{II})$. Note that the surfactant isotherm is different to that shown in Figure 3. In fact, whereas in Figure 3 BAC adsorption reaches a plateau at the CEC of montmorillonite, in Figure 5 BAC adsorption exceeds the $\mathrm{CEC}$ at high $\mathrm{C}_{\mathrm{eq}}$. The difference between experiments in Figures 3 and 4 was the supporting electrolyte used being $\mathrm{NaCl}$ and $\mathrm{NaNO}_{3}$, respectively. Although the anion involved could appear to be unimportant, the $\mathrm{CMC}$ of $\mathrm{BAC}$ in $\mathrm{NaNO}_{3}(1.25 \mathrm{mM})$ is three times lower than in $\mathrm{NaCl}$ $(3.69 \mathrm{mM})$, indicating that the presence of nitrate promotes tail-to-tail interactions. 
If, as it occurs with surface micellisation of $\mathrm{BAC}$ in $\mathrm{NaCl}$ solutions, surface micellisation in $\mathrm{NaNO}_{3}$ takes place at concentrations one order of magnitude lower than the CMC, $\mathrm{BAC}$ adsorption exceeding the $\mathrm{CEC}$ should be observed already at $\mathrm{C}_{\mathrm{eq}}$ around $0.12 \mathrm{mM}$, as it is shown in Figure 5.

Figure 4 Adsorption isotherms of (a) PQ and (b) BAC on montmorillonite at different BAC/PQ ratios: $(\boldsymbol{\square})$ pure PQ; $(\triangle) 0.1 ;(\boldsymbol{\Delta}) 0.5 ;(\diamond) 1 ;(\diamond) 2 ;(\bigcirc) 3 ;(\bullet)$ pure BAC. The lines are drawn to improve the visualisation
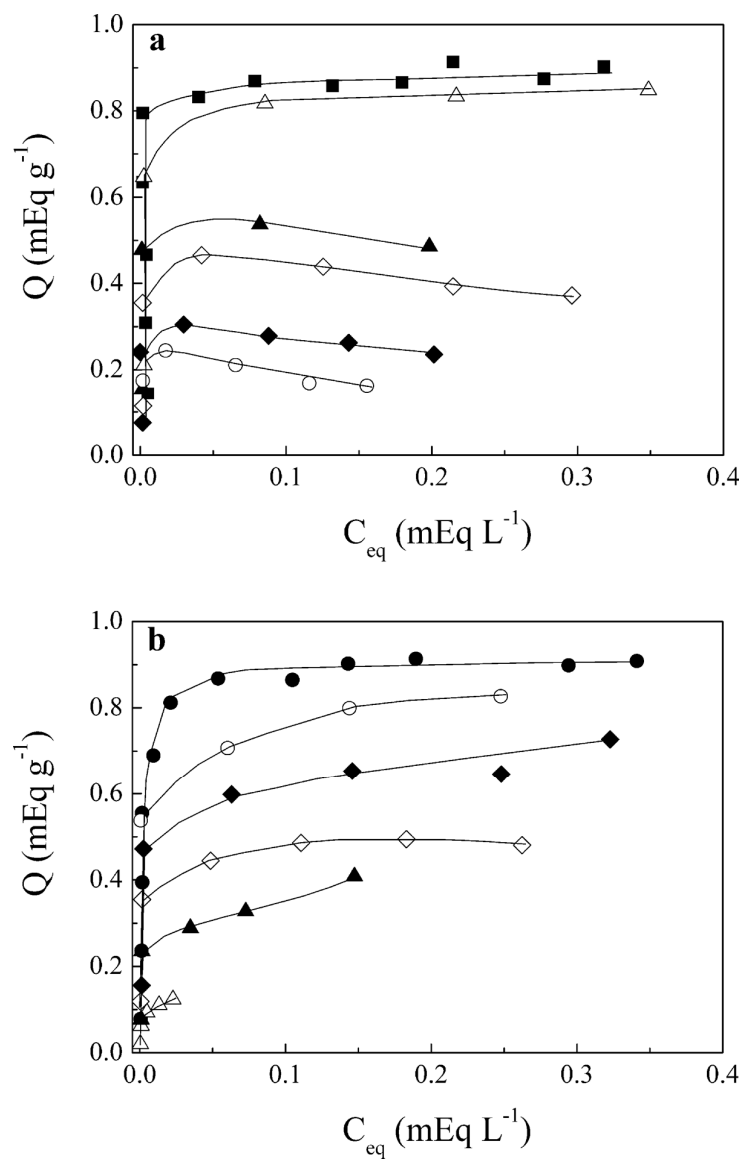

Figure 6 shows the $\mathrm{Cd}(\mathrm{II})$ and the BAC adsorption isotherms in binary solute systems. Five of the 10 measured $\mathrm{Cd}(\mathrm{II})$ isotherms at different BAC concentrations are shown in Figure 6(a). Cd(II) adsorption decreases significantly by increasing BAC concentration. On the contrary, the increase in $\mathrm{Cd}$ (II) concentration does not modify appreciably BAC adsorption (Figure 6(b)). Since BAC adsorption is much stronger that $\mathrm{Cd}(\mathrm{II})$ adsorption, it is clear that in binary solute systems BAC will displace $\mathrm{Cd}(\mathrm{II})$ from adsorption sites but Cd(II) will have a small effect on BAC adsorption. This behaviour is similar to that found by Undabeytia et al. (1999) for the adsorption of mixtures of the cationic herbicide chlordimeform and $\mathrm{Cd}(\mathrm{II})$ on montmorillonite: $\mathrm{Cd}(\mathrm{II})$ adsorption decreased as much as $12 \%$ for a 10 -fold increase in chlordimeform concentration, whereas the herbicide adsorption only decreased by about $2 \%$ for a 6 -fold increase in cadmium concentration. 
Figure 5 Adsorption isotherms of $\mathrm{Cd}(\mathrm{II})(\boldsymbol{\Delta})$ and $\mathrm{BAC}(\boldsymbol{\bullet})$ on montmorillonite

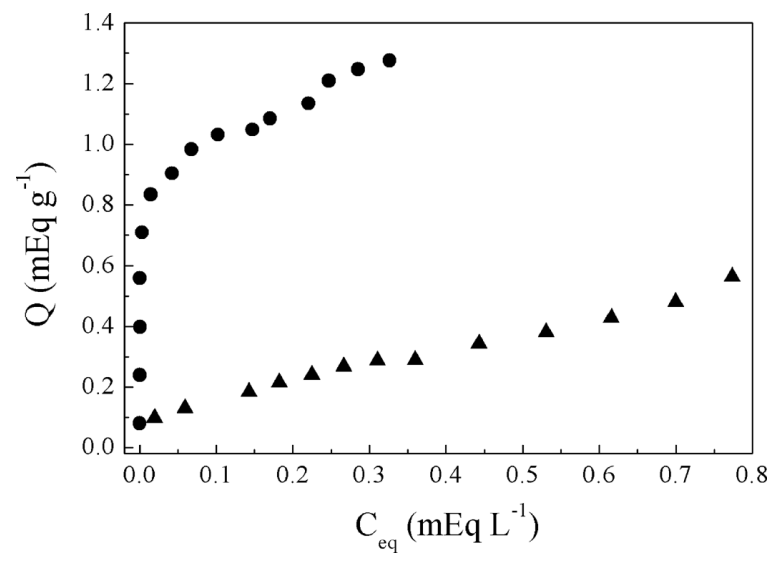

Figure 6 (a) Adsorption isotherms of $\mathrm{Cd}(\mathrm{II})$ on montmorillonite at different initial concentrations

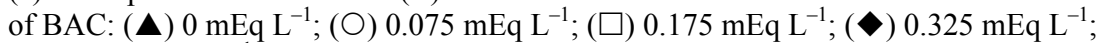
$(\triangle) 0.575 \mathrm{mEq} \mathrm{L}^{-1}$ and (b) adsorption isotherms of BAC on montmorillonite at different initial concentrations of Cd(II): ( $(\bullet) 0 \mathrm{mEq} \mathrm{L}^{-1}$; ( $\star$ ) $0.125 \mathrm{mEq} \mathrm{L}^{-1}$; (口) $0.175 \mathrm{mEq} \mathrm{L}^{-1} ;(\boldsymbol{\nabla}) 0.225 \mathrm{mEq} \mathrm{L}^{-1} ;(\diamond) 0.275 \mathrm{mEq} \mathrm{L}^{-1} ;(\diamond) 0.325 \mathrm{mEq} \mathrm{L}^{-1}$;

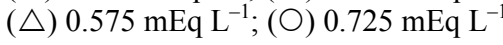
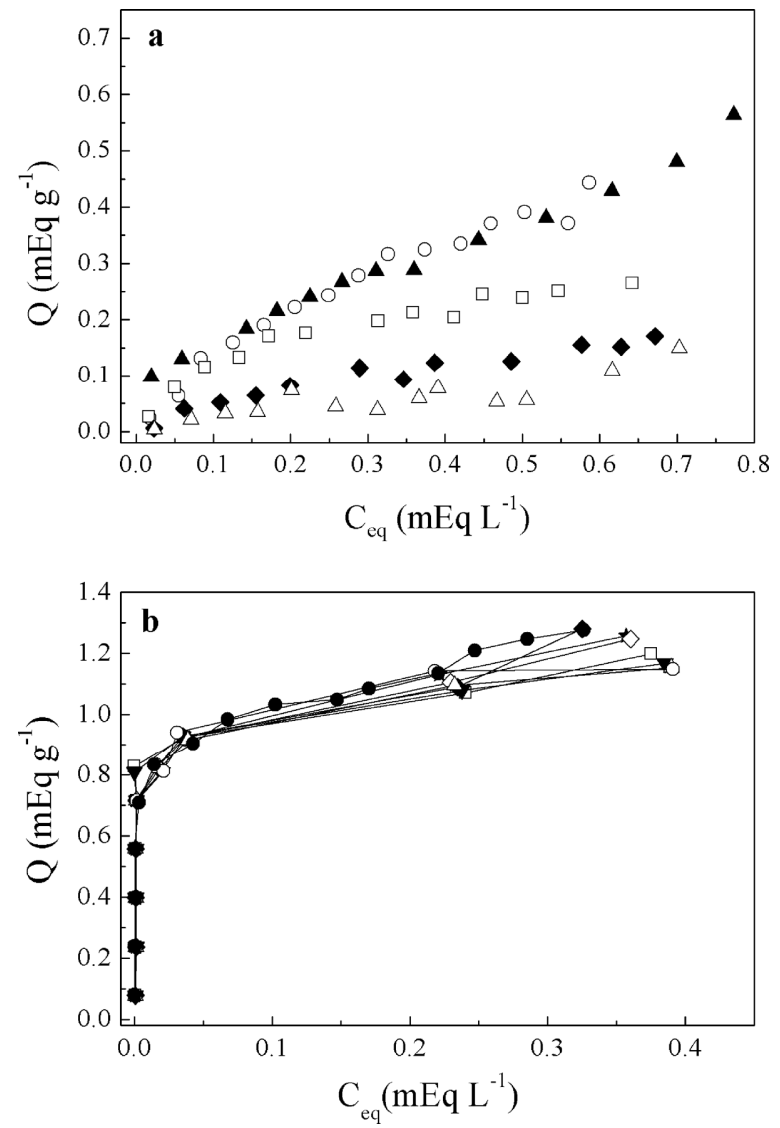


\section{Conclusions}

The results presented in this paper show that BAC affects significantly the adsorption of PQ and $\mathrm{Cd}(\mathrm{II})$ on the montmorillonite surface. This behaviour is assigned to the strong affinity of BAC for the negatively charged montmorillonite surface, competing with the pesticide and the heavy metal for the same surface sites. It seems that mainly electrostatic interactions drive the adsorption. The affinities of BAC and PQ for the montmorillonite surface are rather strong and similar, thus the presence of BAC decreases appreciably the adsorption of $\mathrm{PQ}$, and vice versa. On the contrary, the affinity of $\mathrm{Cd}(\mathrm{II})$ for the montmorillonite surface is much lower than the affinity of BAC, then the presence of BAC affects $\mathrm{Cd}(\mathrm{II})$ adsorption, but the presence of $\mathrm{Cd}(\mathrm{II})$ has no influence on BAC adsorption.

As a general conclusion, although surfactants are usually considered as non-polluting substances and they are spread into the environment without any control, they may have harmful consequences. Their environmental presence would affect the mobility and bioavailability of pesticides and heavy metals, and thus they are substances of immediate concern.

\section{References}

Atun G., Tunçcay, M., Hisarli, G., Talman, R.Y. and Hoşgönmez, H. (2010) 'Adsorption equilibria between dye and surfactant in single and binary systems onto geological materials', Applied Clay Science, Vol. 45, pp.254-261.

Avena, M. and De Pauli, C.P. (1998) 'Proton adsorption and electrokinetics of an argentinean montmorillonite', Journal of Colloid and Interface Science, Vol. 202, pp.195-204.

Baes Jr., Ch.F. and Mesmer, R.E. (1976) The Hydrolysis of Cations, John Wiley \& Sons, Inc., New York.

Bedmar F., Daniel, P.E., Costa, J.L. and Giménez, D. (2011) 'Sorption of acetochlor, S-metolachlor, and atrazine in surface and subsurface soil horizons of Argentina', Environmental Toxicology and Chemistry, Vol. 30, pp.1990-1996.

Bhattacharyya, K.G. and Gupta, S.S. (2008) 'Adsorption of a few heavy metals on natural and modified kaolinite and montmorillonite: a review', Advances in Colloid and Interface Science, Vol. 140, pp.114-131.

Bottoni, P., Grenni, P., Lucentini, L. and Barra Caracciolo, A. (2013) 'Terbuthylazine and other triazines in Italian water resources', Microchemical Journal, Vol. 107, pp.136-142.

Bourg, I.C., Sposito, G. and Bourg, A.C.M. (2007) 'Modeling the acid-base surface chemistry of montmorillonite', Journal of Colloid and Interface Science, Vol. 312, pp.297-310.

Bradbury, M.H. and Baeyens, B. (1997) 'A mechanistic description of $\mathrm{Ni}$ and $\mathrm{Zn}$ sorption on Na-montmorillonite. Part II: modelling', Journal of Contaminant Hydrology, Vol. 27, pp.223-248.

Carrer, S. and Leardi, R. (2006) 'Characterizing the pollution produced by an industrial area Chemometric methods applied to the Lagoon of Venice', Science of The Total Environment, Vol. 370, pp.99-116.

Edser, C. (2008) 'Status of global_surfactants market', Focus on Surfactants, Vol. 11, pp.1-2.

Environmental Protection Agency (EPA) (2006) Prevention, Pesticides and Toxic Substances, (7510C), EPA739-R-06-009.

Esumi K., Takeda, Y. and Koide Y., (1998) 'Competitive adsorption of cationic surfactant and pesticide on laponite', Colloids and Surfaces A: Physicochemical and Engineering Aspects, Vol. 135, pp.59-62. 
Feng, H., Cochran, J.K., Lwiza, H., Brownawell, B.J. and Hirschberg, D.J. (1998) 'Distribution of heavy metal and PCB contaminants in the sediments o fan urban estuary: the Hudson River', Marine Environmental Research, Vol. 45, No. 1, pp.69-88.

Ferrer, I. and Furlong, E.T. (2001) 'Identification of alkyl dimethylbenzylammonium surfactants in water samples by solid-phase extraction followed by ion trap LC/MS and LC/MS/MS for analysis of benzalkonium chlorides in sediment samples', Environmental Science \& Technology, Vol. 35, pp.2583-2588.

Ferrer, I. and Furlong, E.T. (2002) 'Accelerated solvent extraction followed by on-line solid-phase extraction coupled to ion trap LC/MS/MS for analysis of benzalkonium chlorides in sediment samples', Analytical Chemistry, Vol. 74, pp.1275-1280.

Few A.V. and Ottewill, R.H. (1956) 'A spectrophotometric method for the determination of cationic detergents', Journal of Colloid Science, Vol. 11, pp.34-38.

$\mathrm{Fu}, \mathrm{F}$. and Wang, K. (2011) 'Removal of heavy metal ions from wastewaters: a review', Journal of Environmental Management, Vol. 92, pp.407-418.

Gevao, B., Semple, K.T. and Jones, K.C. (2000) 'Bound pesticide residues in soils: a review', Environmental Pollution, Vol. 108, pp.3-14.

Gupta, S.S. and. Bhattacharyya, K.G., (2008) 'Immobilization of $\mathrm{Pb}(\mathrm{II}), \mathrm{Cd}(\mathrm{II})$ and $\mathrm{Ni}(\mathrm{II})$ ions on kaolinite and montmorillonite surfaces from aqueous medium', Journal of Environmental Management, Vol. 87, pp.46-58.

Han, Y-S., Lee, S-Y., Yang, J-H., Hwang, H.S. and Park, I. (2010) 'Paraquat release control using intercalated montmorillonite compounds', Journal of Physics and Chemistry of Solids, Vol. 71, pp.460-463.

Hayes, K.F., Chen, C-C. and McAvoy, D.C. (1995) 'Quaternary ammonium surfactant effects on sorption of trace metals onto quartz and aluminosilicates', Soil Science Society of American Journal, Vol. 59, pp.380-387.

Hillocks, R.J. (2012) 'Farming with fewer pesticides: EU pesticide review and resulting challenges for UK agriculture', Crop Protection, Vol. 31, pp.85-93.

Holmberg, K., Jönsson, B., Kronberg, B. and Lindman, B. (2006) Surfactants and Polymers in Aqueous Solution, 2nd ed., John Wiley \& Son, Ltd, England.

Iglesias Gimenez, E., Sánchez Martín, M.J. and Sánchez Camazzaro, M. (1996) 'Pesticide adsorption in a soil-water system in the presence of surfactant', Chemosphere, Vol. 32, No. 9, pp.1771-1782.

Krogh, K.A., Halling-Sørensen, B., Mogensen, B.B. and Vejrup, K.V. (2003) 'Environmental properties and effects of nonionic surfactant adjutants in pesticides: a review', Chemosphere, Vol. 50, pp.871-901.

Kümmerer, K., Eitel, A., Braun, U., Hubner, P., Daschner, F., Mascart, G., Milandri, M., Reinthaler, F. and Verhoef, J. (1997) 'Analysis of benzalkonium chloride in the effluent from European hospitals by solid-phase extraction and high-performance liquid chromatography with post-column ion-pairing and fluorescence detection', Journal of Chromatography, Vol. 774, pp.281-286.

Kwolek, T., Hodorowicz, M., Stadnicka, K. and Czapkiewicz, J. (2003) 'Adsorption isotherms of homologous alkyldimethylbenzylammonium bromides on sodium montmorillonite', Journal of Colloid and Interface Science, Vol. 264, pp.14-19.

Larsen, J.L., Durink, J. and Skov, H. (2007) 'Trends in chronic marine oil pollution in Danish waters assessed using 22 years of beached bird surveys', Marine Pollution Bulletin, Vol. 54, pp.1333-1340.

Li, X. and Brownawell, B.J. (2010) 'Quaternary ammonium compounds in urban estuarine sediment environments - a class of contaminants in need of increasing attention?', Environmental Science \& Technology, Vol. 44, pp.7561-7568.

Li, Z., Alessi, D. and Allen, L. (2002) 'Heavy metals in the environment. Influence of quaternary ammonium on sorption of selected metal cations onto clinoptilolite zeolite', Journal of Environmen1tal Quality, Vol. 31, pp.1106-1114. 
McArthur, J.M., Sikdar, P.K., Hoque, M.A. and Ghosal, U. (2012) 'Waste-water impacts on groundwater: $\mathrm{Cl} / \mathrm{Br}$ ratios and implications for arsenic pollution of groundwater in the Bengal Basin and Red River Basin, Vietnam', Science of The Total Environment, Vol. 437, pp.390-402.

Meier L.P. and Kahr, G. (1999) 'Determination of the cation exchange capacity (cec) of clay minerals using the complexes of copper(II) ion with Triethylenetetramine and tetraethylenepentamine', Clays and Clay Minerals, Vol. 47, pp.380-388.

Rytwo, G., Nir, S. and Margulies, L. (1996) 'A model for adsorption of divalent organic cations to montmorillonite', Journal of Colloid and Interface Science, Vol. 181, pp.551-560.

Salehian E., Khodadadi, A. and Hosseini, B. (2012) 'Remediation of diesel contaminated soils using surfactants: column study’, American Journal of Environmental Sciences, Vol. 8, pp.352-359.

Séquaris, J.M., Klumpp, E. and Vereecken, H. (2013) 'Colloidal properties and potential release of water-dispersible colloids in an agricultural soil depth profile', Geoderma, Vols. 193-194, pp.94-101.

Slack, R.J., Gronow, J.R. and Voulvoulis, N. (2005) 'Review household hazardous waste in municipal landfills: contaminants in leachate', Science of The Total Environment, Vol. 337 pp.119-137.

Spark, D. (2003) Environmental Soil Chemistry, 2nd ed., Academic Press, New York.

Tahani, A., Karroua, M., Van Damme, H., Levitz, P. and Bergaya, F. (1999) 'Adsorption of a cationic surfactant on $\mathrm{Na}$-montmorillonite: inspection of adsorption layer by $\mathrm{X}$-ray and fluorescence spectroscopies', Journal of Colloid and Interface Science, Vol. 216, pp.242-249.

Undabeytia T., Nir, S., Polubesova, T., Rytwo, G., Morillo, R. and Maqueda, C. (1999) 'Adsorption-desorption of chlordimeform on montmorillonite: effect of clay aggregation and competitive adsorption with cadmium', Environmental Science \& Technology, Vol. 33, pp.864-869.

Van de Voorde, A., Lorgeoux, C., Gromaire, M. and Chebbo, G. (2012) 'Analysis of quaternary ammonium compounds in urban stormwater samples', Environmental Pollution, Vol. 164, pp.150-157.

Zanini, G.P., Maneiro, C., Waiman, C., Galantini, J.A. and Rosell, R.A. (2009) 'Adsorption of metsulfuron-methyl on soils under no-till system in semiarid Pampean Region, Argentina', Geoderma, Vol. 149, pp.110-115.

Zanini, G.P., Ovesen, R.K., Hansen, H.C.B. and Strobel, B.W. (2013) 'Adsorption of the disinfectant benzalkonium chloride on montmorillonite. Synergistic effect in mixture of molecules with different chain lengths', Journal of Environmental Management, Vol. 128, pp.100-105. 